\title{
REFUGIADOS AMBIENTAIS: MUDANÇAS CLIMÁTICAS E RESPONSABILIDADE INTERNACIONAL
}

\author{
M. C. S. ANDRADE ${ }^{1 *}$ e P. D. ANGELUCCI ${ }^{2}$ \\ ${ }^{1}$ Universidade Federal Rural do Rio de Janeiro \\ ${ }^{2}$ Universidade Federal Fluminense \\ mario.csa@hotmail.com*
}

Artigo submetido em fevereiro/2016 e aceito em maio/2016

DOI: $10.15628 /$ holos.2016.4165

\section{RESUMO}

O presente artigo investigou a ausência de tutela jurídica específica para refugiados ambientais e a necessidade de ampliação dos conceitos e práticas de responsabilização internacional para o amparo a esses migrantes forçados. Partindo de dados quantitativos e geográficos sobre os refugiados na atualidade, são analisadas alternativas de normatização do instituto e a possibilidade de responsabilização internacional objetiva dos Estados por dano ambiental e pelos consequentes refugiados.
Metodologicamente, a pesquisa qualitativa valeu-se de fontes bibliográficas e normativas, nacionais e internacionais, e dados estatísticos sobre o tema. Concluiu-se pela responsabilização internacional dos Estados, em especial dos economicamente desenvolvidos, pelos deslocamentos populacionais decorrentes de mudanças climáticas, por serem os principais poluidores ambientais.

PALAVRAS-CHAVE: Refúgio ambiental, Mudanças climáticas, Responsabilidade internacional.

\section{ENVIRONMENTAL REFUGEES: CLIMATE CHANGE AND INTERNATIONAL LIABILITY}

\begin{abstract}
This paper investigated the absence of specific legal protection for environmental refugees and the need to expand the concepts and international accountability practices for the protection of these forced migrants. Using recent quantitative and geographical data on refugees, alternatives for the regulation of the institute and the possibility of objective international State responsibility for environmental damage and for the resulting refugees are analyzed. Methodologically, the
\end{abstract}

qualitative research was based on national and international bibliography and normative sources, as well as on statistical data on the subject. As a conclusion, it is advocated the international responsibility of States, especially the economically developed ones, for the population movements which result from climate change, since these States are the main environmental polluters.

KEYWORDS: Environmental refuge, Climate change, International liability. 


\section{INTRODUÇÃO}

As sucessivas levas de refugiados que tem aportado recentemente na Europa colocaram, mais uma vez, o problema dos refugiados no centro das atenções internacionais, instaurando uma disputa entre Estados pela divisão do ônus do refúgio, além de alimentar o fantasma da xenofobia, sempre a rondar o velho continente.

As mudanças climáticas sofridas pelo globo têm potencializado esses deslocamentos populacionais. Contudo, a ausência de normas internacionais regulamentadoras do refúgio ambiental tem obstado a responsabilização dos Estados pelos danos ambientais e consequentes migrações forçadas.

Porém, defende-se que os refugiados ambientais podem ser beneficiados pela aplicação da teoria do risco à ocorrência de dano ambiental causado, ainda que indiretamente, por países poluidores. A partir de uma concepção teórica construtivista de valorização e proteção do indivíduo, defende-se a ampliação do marco de responsabilização objetiva do Estado para abarcar o refúgio ambiental.

A presente pesquisa qualitativa valeu-se de fontes institucionais, bibliográficas e dos mais recentes dados internacionais sobre deslocamento ambiental na atualidade, tendo caráter jurídico-propositivo ao apontar alternativas para a responsabilização internacional por migrações forçadas por causas ambientais.

\section{REFUGIADOS AMBIENTAIS: CONCEITO E TUTELA INTERNACIONAL}

O instituto jurídico do refúgio possui como principal regulamentação internacional a Convenção Relativa ao Estatuto dos Refugiados (1951) e o Protocolo sobre o Estatuto dos Refugiados (1966). No Brasil, o principal diploma normativo é a Lei no 9.474, de 1997. Em consonância com as normas internacionais, o artigo 10 da Lei no 9.474 (BRASIL, 1997) estabelece que a qualificação de refugiado decorre de perseguição por motivos de etnia, religião ou nacionalidade, ou por pertencer a específico segmento social.

Contrariamente ao asilo e a outros institutos do direito internacional referentes a casos de natureza política ou ideológica, de caráter mais individual, o refúgio está relacionado a questões coletivas, como situações de grande penúria. No refúgio propriamente dito, inúmeros indivíduos são obrigados a se deslocar a partir de seus Estados de origem em direção a outro local onde possam viver sob melhores condições (JUBILUT; APOLINÁRIO, 2010).

Diplomas regionais podem ampliar as hipóteses de concessão de refúgio, como fez a Declaração de Cartagena sobre os Refugiados, de 1984, que incluiu as hipóteses de ameaça de violência generalizada, agressão interna e violação massiva de direitos humanos (ACNUR, 1984). Nesse sentido, a Lei no 9.474/97 (art. 1으, inc. III) prevê a possibilidade de reconhecer como refugiado aquele que, devido a grave e generalizada violação de direitos humanos, é obrigado a deixar seu país de nacionalidade para buscar abrigo em outro Estado. Assim, a lei brasileira, mais recente que o Protocolo de 1966 e a Convenção de 1951, adota definição mais ampla de refugiado, indo além dos casos de perseguição por motivo de etnia, religião e nacionalidade. 
Nos art. 2ำ e 3ำ da Lei no 9.474 (BRASIL, 1997), a delimitação de quem será considerado refugiado se dá através de hipóteses de extensão e exclusão. A lei traz especificações sobre os direitos e deveres dos refugiados, o ingresso no território nacional e o pedido de refúgio. Ela disciplina, também, os processos de extradição, expulsão e perda da condição de refugiado e das chamadas soluções duráveis, que consistem na repatriação, integração local e reassentamento do refugiado. A lei criou, ainda, o Comitê Nacional para os Refugiados (CONARE), órgão de deliberação colegiada, integrante do Ministério da Justiça.

Apesar da significativa proteção jurídica nacional e internacional dispensada ao refugiado, ela não contempla um caso particular: o refugiado ambiental. As condições ambientais não são oficialmente elencadas como causa jurídica para a concessão de refúgio.

O termo refugiado ambiental foi popularizado a partir de publicação do professor Essam ElHinnawi, do Egyptian National Research Centre, em 1985. A definição foi aplicada aos indivíduos forçados a deixarem seu habitat natural, de forma temporária ou permanente, em função de significativa perturbação ambiental (natural e/ou desencadeada pela ação humana) que tenha colocado em risco sua existência e/ou afetado seriamente sua qualidade de vida (MORRISSEY, 2012).

O relatório The Government Office for Science, do Reino Unido, sugere algumas vias para lidar com as lacunas normativas em relação aos migrantes forçados por causas ambientais, como os instrumentos de soft law, os princípios orientadores de deslocamento interno e os princípios Nansen, que oferecem diretrizes para o trabalho relacionado às vítimas de mudanças climáticas (REINO UNIDO, 2011).

Embora não possuam status de norma jurídica, as normas de soft law representam uma obrigação moral do Estado e têm dupla finalidade: (1) fixar metas para futuras ações políticas nas relações internacionais e (2) recomendar aos Estados que adequem as normas de seu ordenamento interno às regras internacionais contidas na soft law.

A crescente aposta em instrumentos de soft law decorre da percepção de que, recorrentemente, a solução para impasses internacionais pode não estar em sistemas de proteção formal (rígido), mas em sistemas mais flexíveis.

\section{REFUGIADOS NO MUNDO: DIAGNÓSTICO DO NOSSO TEMPO}

A mais recente edição do relatório Tendências Globais, de 18 de junho de 2015, registra um crescimento recorde no número de refugiados no mundo. Há uma década, esse número era de 37,5 milhões de pessoas. Em 2013, ele passou para 51,2 milhões; alcançando, em 2014, o recorde de 59,5 milhões de pessoas (ACNUR, 2015).

Na Somália, mais de 170 mil pessoas fugiram, entre janeiro e julho de 2011, para países próximos, em decorrência de seca, fome e insegurança. Por conta da seca na África Oriental, cerca de 450 mil refugiados somalis foram deslocados para Quênia, Etiópia e Djibuti (ONUBR, 2011).

Estima-se que, em 1995, os refugiados ambientais já totalizavam 25 milhões de pessoas. Destes, cerca de 5 milhões seriam do Sahel africano, fugindo de secas. Em outras regiões da África subsaariana, 80 milhões de pessoas são consideradas semifamintas, por conta, especialmente, de fatores ambientais, e 7 milhões de pessoas foram obrigadas a migrar para obter alimento. Nos 
primeiros meses de 2000, no Sudão, 8 milhões de pessoas foram oficialmente consideradas em risco de fome; na Somália e no Quênia, 3 milhões. Para Myers, considerável parte desses migrantes pode ser caracterizada como refugiados ambientais, visto que a fome foi provocada pela alteração das condições ambientais (MYERS, 2001).

Os sudaneses formam o único grupo de refugiados amplamente reconhecido como ambientais. Apesar de a justificativa formal para a concessão do refúgio ser a guerra civil que durou 22 anos (1983-2005), a degradação do meio ambiente foi aceita como origem dos conflitos. Em razão de fatores como a elevação do índice populacional, o aumento da desertificação no norte do país e a escassez de recursos naturais, a maioria árabe e muçulmana que habitava a região foi levada deslocar-se para o sul, onde os negros cristãos permaneciam como dominantes. A guerra entre esses grupos causou 300 mil mortes e forçou a migração de 2,7 milhões de pessoas.

De acordo com o relatório do Painel Intergovernamental sobre Mudanças Climáticas (IPCC), denominado Mudanças climáticas 2014: Impactos, adaptação e vulnerabilidade, por volta do ano de 2001, 50 milhões de pessoas já seriam consideradas refugiadas devido a causas ambientais e, provavelmente, este número chegará a 1 bilhão até 2050. O referido estudo da Organização das Nações Unidas (ONU) destaca, ainda, que, se as previsões de elevação do nível dos oceanos se concretizarem, algumas nações desaparecerão, aumentando o número de deslocados ambientais (ONU, 2014).

Estudo realizado pelo Centro de Estudos sobre Refúgio, da Universidade de Oxford, coletou dados sobre o deslocamento ambiental forçado em países como Quênia, Gana e Bangladesh. Segundo o estudo, no Quênia, a migração está estreitamente ligada a questões de terra, que é o principal meio de subsistência para a vasta maioria dos quenianos, ainda que apenas $20 \%$ do território nacional seja fértil. Além disso, a colonização baseada no confisco de terras e na remoção forçada dos nativos privou grande número de pessoas desse meio de subsistência. Ademais, as comunidades pastoris tradicionais estão cada vez mais suscetíveis à vulnerabilidade dos ecossistemas e às mudanças climáticas. Consequentemente, já em 2007, os deslocados do Quênia totalizavam cerca de 660.000 (ZETTER, 2011).

Em Bangladesh, as inundações de 1988 e 1998 deslocaram, respectivamente, 45 e 30 milhões de pessoas, enquanto o ciclone Aila deslocou 74.500 famílias, só em 2009. Estima-se que uma elevação de 01 metro do nível dos oceanos provocará, até 2050, o deslocamento forçado de 13 a 40 milhões de pessoas, caso não sejam adotadas quaisquer medidas de adaptação (ZETTER, 2011).

Em Gana, entre 1991 e 2009, estima-se que até 3.650.000 pessoas foram temporariamente deslocadas, principalmente, por desastres naturais. A escassez de terras férteis para agricultura, chuva irregular e baixa produtividade das culturas e/ou problemas de segurança alimentar representaram, juntas, 90\% de todas as razões para deslocamentos (ZETTER, 2011).

\section{RESPONSABILIDADE INTERNACIONAL POR DANO AMBIENTAL}

\subsection{Responsabilidade internacional subjetiva e objetiva}

O instituto da responsabilidade civil trata da obrigação de reparação de danos imputada a alguém por conta de uma ação ou omissão. Esse instituto foi muito negligenciado pela doutrina 
internacionalista por não haver um poder central global, o que dificultaria eventual imposição de obrigação de reparação ao Estado responsável por dano. Alega-se que tal imposição afrontaria a soberania nacional do Estado (REIS, 2010, p. 33).

Todavia, o Direito internacional contemporâneo tem revisto essa interpretação, devido ao maior destaque dado ao direito de cooperação e à proteção dos direitos humanos. Atualmente, percebe-se que certas situações, ainda que ocorridas dentro dos limites territoriais nacionais, têm repercussões globais, não podendo, portanto, estarem sob a absoluta discricionariedade estatal, sendo passíveis de interferência pela comunidade internacional (REIS, 2010, p. 34).

A doutrina internacionalista elenca três elementos que devem estar presentes para a responsabilização internacional subjetiva do Estado: (1) o ato ilícito internacional; (2) a imputabilidade; e (3) prejuízo ou dano a outro Estado (BEDRAN; MAYER, 2013, p. 51).

O ato ilícito consiste na violação de norma de Direito Internacional por ação ou omissão. Já imputabilidade é a possibilidade de o ato antijurídico ser atribuível ao Estado enquanto sujeito de Direito Internacional Público. Segundo Reis (2010, p. 99), o Estado tem, portanto, deveres pelos quais responde em caso de dano a outro, devendo-lhe ser imputada a respectiva obrigação de reparação.

Porém, no âmbito da responsabilidade civil internacional do Estado por ato ilícito, não há qualquer regulamentação em vigor. Assim, Reis opta por se orientar por um Draft de artigos sobre o tema que foi aprovado pela Comissão de Direito Internacional (CDI) da ONU. Ainda que não esteja plenamente em vigor e permaneça pendente de assinaturas, o Draft sintetiza a evolução da jurisprudência internacional, evidenciando o entendimento e a proposta de um órgão oficial internacional com ampla experiência no tema (REIS, 2010, p. 99-100).

Já a responsabilidade civil por ato lícito, depende de previsão expressa em tratados internacionais, uma vez que não decorre da infração de um dever jurídico. Há uma norma que imputa determinado resultado fático a um agente, imputando-lhe a responsabilidade sobre a ocorrência do evento, independentemente de culpa. Essa é a responsabilidade objetiva, que se baseia na aplicação da chamada teoria do risco (REIS, 2010, p. 100).

A doutrina objetivista da teoria do risco defende que, para a responsabilização civil do Estado, basta o nexo de causalidade entre o dano relacionado a direitos humanos e preservação do meio ambiente, sendo irrelevante perscrutar as circunstâncias que levaram o Estado à produção do dano (REIS, 2010, p. 100).

Para a teoria objetivista, a responsabilidade do Estado surge a partir do momento em que se verifica a existência de nexo de causalidade entre a conduta (comissiva ou omissiva) do Estado e o dano, sendo indiferente para a caracterização da responsabilidade o elemento psicológico do causador. Não se se discute culpa, importando apenas o risco assumido pelo Estado ao praticar o ato com potencialidade de causar dano. Trata-se de responsabilidade por risco, cujo aparecimento na seara internacional se deu a partir da segunda metade do séc. XX (REIS, 2010, p. 39).

Assim, eventos lícitos, mas causadores de risco iminente e excepcional, como testes nucleares e poluição marítima por hidrocarbonetos, podem acarretar a responsabilização internacional do Estado.

Todavia, a responsabilidade objetiva depende de expressa previsão em tratado, sendo necessária norma que impute a alguém a responsabilidade pelo dano, a despeito da licitude da 
conduta. Daí a importância da admissão da categoria de refugiado ambiental, pois sem norma que a regule, não há como aplicar aos casos concretos a responsabilidade objetiva.

Enquanto corpo jurídico especializado com a atribuição de preparar projetos de convenções sobre temas ainda não regulamentados pela legislação internacional e de codificar as regras do direito internacional nos campos onde já existe uma prática do Estado, a CDI propõe a dispensa de aferição de culpa até mesmo para atos ilícitos, por entender que o importante para a responsabilização do Estado é a previsão em norma jurídica.

Constata-se que a teoria objetiva é a que confere maior segurança diante da complexidade de fatores e agentes das relações internacionais. No atual cenário globalizado, a dificuldade na aferição da culpa pode impossibilitar a atribuição de responsabilidade, a reparação do dano e o socorro às vítimas.

\subsection{Soft law como alternativa}

No direito ambiental, verifica-se forte tendência à adoção de convenções-quadro (umbrella conventions). De acordo com esse tipo de instrumento, é estabelecida, primeiramente, uma convenção de caráter geral e com natureza de soft law, prevendo os princípios, resoluções e códigos de conduta; assinada esta convenção geral, cabe a protocolos específicos a regulamentação dos assuntos apontados na convenção; após assinados, os protocolos tem poder vinculativo e coercitivo. Por exemplo, o Protocolo de Kyoto complementa a Convenção-Quadro das Nações Unidas sobre Mudanças Climáticas (ORELLANA, 2010, p. 158).

Conforme Reis (2010, p. 17-19), soft law é norma jurídica de conteúdo programático. Além de representar deveres morais e políticos, ela prescreve a adequação das leis e políticas internas dos Estados ao seu conteúdo. Assim, apesar da regra de não responsabilização internacional por descumprimento de soft law, a imputação pode ocorrer quando, no caso concreto, o descumprimento do pactuado causar danos a terceiros, sob pena de contradição com o dever moral internacionalmente assumido.

Considerando-se que os deslocamentos forçados podem ser causados por alterações ambientais provocadas ou potencializadas pela conduta irresponsável de países poluidores, percebe-se que, para estabelecer uma rede de proteção adequada e eficaz aos deslocados ambientais, os Estados, em especial os altamente industrializados, devem ser responsabilizados pelos deslocamentos populacionais decorrentes de mudanças climáticas, afinal, terão assumido o risco da produção de danos ambientais, como as consequências do efeito estufa.

Tradicionalmente, a responsabilidade objetiva ou por risco decorre de convenções internacionais sobre matérias específicas. Todavia, a CDI defende que essa responsabilidade pode decorrer de uma codificação genérica, por antever que a vastidão do tem dificultado a produção rápida de uma regulamentação abrangente e consensual.

\section{CONCLUSÃO}

Apesar de os fluxos migratórios serem fenômenos multicausais, o reconhecimento da espécie refúgio ambiental justifica-se quando o desequilíbrio ambiental for principal fator causante das condições que forçam o deslocamento populacional. Entretanto, a ausência de normas 
internacionais tem dificultado a assistência a esses refugiados e obstado a responsabilização dos Estados.

Uma alternativa seria a abordagem oferecida pelas normas de soft law. Tais normas representam uma obrigação moral do Estado, fixando metas para futuras ações políticas nas relações internacionais e demandando coerência dos Estados, que devem adequar seu ordenamento e suas políticas públicas a essas normas internacionalmente pactuadas.

Quando se trata da responsabilidade objetiva por atos lícitos praticados pelos Estados, a responsabilização é sempre resultado de normas expressas sobre matérias pré-determinadas, como é o caso de alguns tipos de dano ambiental. Todavia, a melhor proteção parece ser a proposta pela CDI de uma codificação genérica das regras sobre responsabilidade estatal por dano ambiental. Essa estratégia evitaria que um dano ambiental deixe de ser reparado pela ausência de previsão específica e, principalmente, que as vítimas desse dano, como os migrantes forçados, fiquem desamparados. O efeito estufa, o aquecimento global e suas consequências devem ser considerados como dano produzido por todos, destacadamente, pelos países desenvolvidos, que são os maiores poluidores do meio ambiente, em razão, por exemplo, do volume de dióxido de carbono emitido por seus parques industriais. Assim, esses mesmos países devem ser responsabilizados internacionalmente pelas vítimas de suas condutas poluidoras que tanto têm colaborado para o aumento do número de refugiados ambientais, partilhando a obrigação de conceder refúgio e de financiar medidas internacionais de reparo, socorro e adaptação.

\section{REFERÊNCIAS BIBLIOGRÁFICAS}

1. ACNUR. Alto Comissariado das Nações Unidas para Refugiados. ACNUR: Refugiados sírios já passam dos 4 milhões. p. em 09 de julho de 2015. Disponível em: <http://www.acnur.org/t3/portugues/noticias/noticia/acnur-refugiados-sirios-ja-passamdos-4-milhoes/>. Acesso em: 15 dez. 2015.

2. _. Declaração de Cartagena sobre os Refugiados, de 22 de novembro de 1984. Disponível em: <www.acnur.org/t3/fileadmin/.../BD.../Declaracao_de_Cartagena.pdf?>. Acesso em: 10 jan. 2016.

3. BEDRAN, Karina Marcos; MAYER, Elizabeth. A responsabilidade civil por danos ambientais no direito brasileiro e comparado: teoria do risco criado versus teoria do risco integral. Veredas do Direito, jan./jun., v. 10, n. 19, Belo Horizonte: ESDHC, p. 45-88, 2013.

4. BRASIL. Lei $\mathbf{n} \mathbf{9} \mathbf{9 . 4 7 4}$, de 22 de julho de 1997. Define mecanismos para a implementação do Estatuto dos Refugiados de 1951, e determina outras providências. Disponível em: <http://www.planalto.gov.br/ccivil_03/Leis/L9474.htm>. Acesso em: 10 jan. 2016.

5. JUBILUT, Liliana Lyra; APOLINÁRIO, Silvia Menicucci O. S. A necessidade de proteção internacional no âmbito da migração. Revista Direito GV, v. 6. São Paulo: FGV, p. 275-294, 2010.

6. MORRISSEY, James. Rethinking the 'debate on environmental refugees': from 'maximilists and minimalists' to 'proponents and critics'. Journal of Political Ecology, vol. 19, 2012. Oxford: University of Oxford Press. Disponível em: <jpe.library.arizona.edu/volume_19/Morris sey.pdf>. Acesso em: 10 dez. 2015.

7. MYERS, Norman. Environmental refugees: our latest understanding, philosophical 
transactions of the Royal Society. (2001). Disponível em: <rstb.royalsocietypublishing.org/ content/357/.../609>. Acesso em: 14 jan. 2016.

8. ONU. Organização das Nações Unidas. Painel intergovernamental sobre mudanças climáticas. Mudanças climáticas 2014: impactos, adaptação e vulnerabilidade. Cambridge: Cambridge University Press, 2014.

9. ONUBR. Organização das Nações Unidas no Brasil. ACNUR comemora 60 anos da convenção de 1951 para refugiados. p. em 28 de julho de 2011. Disponível em: <http://www.onu.org.br/ acnur-comemora-60-anos-da-convencao-de-1951-para-refugiados/>. Acesso em: 14 jan. 2016.

10. ORELLANA, Marcos A. Mudança climática e os objetivos de desenvolvimento do milênio: o direito ao desenvolvimento, cooperação internacional e o mecanismo de desenvolvimento limpo. SUR - Revista internacional de direitos humanos, v. 7, n. 12, p. 153-180, jun., 2010.

11. RAMOS, Erika Pires. Refugiados ambientais: em busca de reconhecimento pelo direito internacional. São Paulo: E. P. Ramos, 2011.

12. REINO UNIDO. The Government Office for Science. Migration and global environmental change: future challenges and opportunities. Final project report. Londres: The Government Office for Science, 2011. Disponível em: <https://www.gov.uk/government/publications/mi gration-and-global-environmental-change-future-challenges-and-opportunities $>$. Acesso em: 10 jan. 2016.

13. REIS, Alessandra de Medeiros Nogueira. Responsabilidade internacional do Estado por dano ambiental. São Paulo: Campus Jurídico, 2010.

14. ZETTER, Roger. Refugee Studies Centre. Oxford Department of International Development. Protecting environmentally displaced people: Developing the capacity of legal and normative frameworks. Oxford: University of Oxford Press, 2011. 